\title{
Transcriptome profiling and pathway analysis of genes expressed differentially in participants with or without a positive response to topiramate treatment for methamphetamine addiction
}

Ming D Li ${ }^{1 *}$, Ju Wang ${ }^{1}$, Tianhua Niu ${ }^{1}$, Jennie Z Ma ${ }^{1}$, Chamindi Seneviratne ${ }^{11}$, Nassima Ait-Daoud ${ }^{1}$, Jim Saadvandi ${ }^{2}$, Rana Morris ${ }^{2}$, David Weiss ${ }^{12}$, Jan Campbell ${ }^{3}$, William Haning ${ }^{4}$, David J Mawhinney ${ }^{5}$, Denis Weis ${ }^{6}$, Michael McCann Christopher Stock ${ }^{8}$, Roberta Kahn ${ }^{9}$, Erin Iturriaga ${ }^{9}$, Elmer Yu ${ }^{10}$, Ahmed Elkashef ${ }^{9}$ and Bankole A Johnson ${ }^{11}$

\begin{abstract}
Background: Developing efficacious medications to treat methamphetamine dependence is a global challenge in public health. Topiramate (TPM) is undergoing evaluation for this indication. The molecular mechanisms underlying its effects are largely unknown. Examining the effects of TPM on genome-wide gene expression in methamphetamine addicts is a clinically and scientifically important component of understanding its therapeutic profile.

Methods: In this double-blind, placebo-controlled clinical trial, 140 individuals who met the DSM-IV criteria for methamphetamine dependence were randomized to receive either TPM or placebo, of whom 99 consented to participate in our genome-wide expression study. The RNA samples were collected from whole blood for 50 TPM- and 49 placebo-treated participants at three time points: baseline and the ends of weeks 8 and 12. Genome-wide expression profiles and pathways of the two groups were compared for the responders and non-responders at Weeks 8 and 12. To minimize individual variations, expression of all examined genes at Weeks 8 and 12 were normalized to the values at baseline prior to identification of differentially expressed genes and pathways.
\end{abstract}

Results: At the single-gene level, we identified 1054, 502, 204, and 404 genes at nominal $P$ values $<0.01$ in the responders vs. non-responders at Weeks 8 and 12 for the TPM and placebo groups, respectively. Among them, expression of 159, 38, 2, and 21 genes was still significantly different after Bonferroni corrections for multiple testing. Many of these genes, such as GRINA, PRKACA, PRKCI, SNAP23, and TRAK2, which are involved in glutamate receptor and GABA receptor signaling, are direct targets for TPM. In contrast, no TPM drug targets were identified in the 38 significant genes for the Week 8 placebo group. Pathway analyses based on nominally significant genes revealed 27 enriched pathways shared by the Weeks 8 and 12 TPM groups. These pathways are involved in relevant physiological functions such as neuronal function/synaptic plasticity, signal transduction, cardiovascular function, and inflammation/immune function.

Conclusion: Topiramate treatment of methamphetamine addicts significantly modulates the expression of genes involved in multiple biological processes underlying addiction behavior and other physiological functions.

Keywords: Topiramate, Pharmacogenetics, Genes, Pathways, Transcriptome, Addiction treatment, Methamphetamine addiction

\footnotetext{
* Correspondence: Ming_Li@virginia.edu

${ }^{1}$ Department of Psychiatry and Neurobehavioral Sciences, University of

Virginia, Charlottesville, USA

Full list of author information is available at the end of the article
} 


\section{Background}

Methamphetamine (METH), an N-methyl derivative of amphetamine commonly abused recreationally, is a powerfully addictive psychostimulant that affects the central nervous system (CNS) dramatically [1]. Dependence on the drug has risen to an epidemic level worldwide [2], and in 2007, 529,000 Americans (ca. $0.2 \%$ of the US population) were METH users [3].

METH induces long-term changes in behavior, including sensitization and dependence $[4,5]$, as well as deficits in cognitive function [6-8], and causes psychiatric symptoms such as hallucinations and delusions [9]. Its use and abuse have been associated with several significant health risks, including cardiac dysrhythmia, stroke, high blood pressure, hyperthermia, and CNS abnormalities $[10,11]$ that are thought to reflect changes in the signaling and metabolism of neurotransmitters such as dopamine, serotonin, and glutamate [10,12-16].

Unfortunately, no efficacious medication for METH dependence has been developed to date [17]. There is a great need, not only for novel treatments, but for understanding of its molecular mechanisms. Topiramate (TPM), a sulfamate-substituted derivative of the monosaccharide D-fructose [18], has been efficacious in the treatment of alcohol dependence [19] and in promoting smoking cessation among alcohol-dependent smokers [20]. A preliminary study suggests that it also may be useful for treating cocaine dependence [21]. These therapeutic effects have been attributed to its hypothesized potential to reduce the release of cortico-mesolimbic dopamine, the neurotransmitter primarily responsible for the acquisition and maintenance of drug-seeking behaviors for the majority of abused drugs, including amphetamines. Thus, TPM might be efficacious for treating METH dependence [22]. However, the effects of TPM on METH-dependent subjects seem to be complex. Whereas earlier studies have not uncovered any deleterious interactions between TPM and METH with respect to cognitive performance, attention, or concentration, TPM tends to enhance METH-induced increases in attention and decrease perceptual-motor function [22]. Also, TPM accentuates markedly the positive subjective effects of $\mathrm{METH}$, although not craving or reinforcement [23]. Although several hypotheses have been offered on the basis of clinical laboratory studies for the effects of TPM on METH dependence [22-25], the molecular mechanisms remain unclear.

In a recently completed double-blind, multi-center, placebo-controlled clinical trial of the treatment of METH dependence with TPM, mixed results were obtained [26]. Thus, although TPM did not increase abstinence from METH use, it significantly reduced urine METH concentrations and observer-rated severity of dependence [26]. From this trial, a genome-wide expression analysis was conducted on RNA extracted from the blood of participants, with the goal of identifying differentially expressed genes and pathways in the responders and non-responders. Such a global gene expression investigation not only provides evidence at the molecular level explaining the interaction of TPM and METH but also may help us to evaluate the pharmacological effect of TPM on METH dependence.

\section{Results \\ Grouping study participants used for transcriptome analysis}

On the basis of 209 chips that passed quality control, 49 participants in the placebo group and 50 in the TPM group were included. According to the criteria for primary efficacy outcome [26] (also see Methods), these participants were classified as responders or nonresponders. For these participants, only 43 had a gene expression study at all three time points, 27 and 24 of which could be classified as responders or nonresponders, respectively. For the other 16 participants, either no valid urine samples were tested or the patients were excluded for other reasons at Weeks 8 and 12 (see Additional file 1: Figure S1). To increase the sample size, we included some participants having valid gene expression data at Week 8 but not at Week 0 (baseline) among the Week 8 samples, as well as those participants with valid gene expression data at both Weeks 8 and 12 but not at baseline. Finally, we identified 5 responders and 17 non-responders in the Week 8 TPM group, 4 responders and 17 non-responders in the Week 8 placebo group (see Additional file 1: Figure S1A), 6 responders and 11 non-responders in the Week 12 TPM group, and 2 responders and 13 non-responders in the Week 12 placebo group (see Additional file 1: Figure S1B).

\section{Identification of genes differentially expressed in responders and non-responders at Weeks 8 and 12}

At a significance level of 0.01, we identified 1,054 (FDR: 0.009 0.010; range $<110^{-5}-0.035$ ), 502 (FDR: 0.027 0.021; range: $<110^{-5}-0.070$ ), 204 (FDR: 0.1130 .034 ; range: $0.003-0.160$ ), and 404 (FDR: 0.0330 .024 ; range: $\left.<110^{-5}-0.084\right)$ differentially expressed genes between responders and non-responders for the Week 8 TPM, Week 8 placebo, Week 12 TPM, and Week 12 placebo groups, respectively (see Additional file 2: Tables S1-S4 for details). Of these four groups, the Week 8 TPM group had the lowest FDR. To take into account the number of genes tested in the four groups, 159, 38, 2, and 21 genes, respectively, remained significant at Bonferronicorrected $\mathrm{P}$ values $<0.05$.

In the Week 8 TPM group, 159 genes were significantly changed with a Bonferroni-corrected $\mathrm{P}$ value of $<0.05$, with 97 being up-regulated and 62 down-regulated comparing positive and negative responders. Importantly, none 
of these 159 genes overlapped with the 38 genes detected in the Week 8 placebo group at a Bonferroni-corrected $\mathrm{P}$ value of 0.05 (Additional file 2: Table S2). Tables 1 and 2 show, respectively, the representative up-regulated and down-regulated genes whose functions are related to cell adhesion/motion, nervous system development and function/synaptic plasticity, signal transduction, ubiquitination/ intracellular protein transport, mitochondrial function/ metabolism and energy pathways, and immune system function categories.

In the Week 12 TPM group, we detected only two genes, ITCH and $M K N K 2$, whose expression remained significant after Bonferroni correction for multiple testing (Additional file 2: Table S3). Both were down-regulated by TPM and are in the nervous system development and function/synaptic plasticity category. Although the exact reason is unknown, we suspect that the small size of the Week 12 TPM group might have contributed. None of them overlapped with those 21 genes changed by placebo at Week 12 with Bonferroni-corrected $\mathrm{P}$ values $<0.05$ (Additional file 2: Table S4).

\section{Pathways identified by IPA}

The differentially expressed genes were subjected to pathway analysis using the IPA. A total of 114, 41, 54, and 25 pathways with at least three genes overexpressed were enriched at a nominal $\mathrm{P}$ value of $<0.05$ between responders and non-responders for Week 8 TPM, Week 8 placebo, Week 12 TPM, and Week 12 placebo, respectively. Among these pathways, 21 significantly enriched pathways with an FDR of $<0.05$ at either time point or $\mathrm{FDR}<0.10$ at both time points were shared exclusively by the Week 8 and Week 12 TPM groups (Table 3), suggesting they are more likely to be the pathways related to the treatment effect of TPM in METH-dependent subjects. No significantly enriched pathways were shared exclusively by the Week 8 and Week 12 placebo groups, with FDRs $<0.10$ at both time points. Although 163, 149,137 , and 120 pathways were detected for the Week 8 TPM, Week 8 placebo, Week 12 TPM, and Week 12 placebo groups, respectively, at a significance level of 0.05 , only $46,5,6$, and 0 pathways remained significant after Bonferroni correction for multiple testing. A comparison of these significant pathways after correction for multiple testing revealed that only two pathways (i.e., Bcell receptor signaling and renin-angiotensin signaling) were shared exclusively by the Week 8 and Week 12 TPM groups, and no pathways were shared by the Week 8 and Week 12 placebo groups.

\section{Pathways identified by onto-tools pathway-express}

Next, we performed pathway analysis on the nominally significantly expressed genes using Onto-Tools PathwayExpress. A total of 47, 21, 32, and 25 KEGG pathways with at least three overexpressed genes were enriched at nominal $\mathrm{P}$ values $<0.05$ between responders and nonresponders for the Week 8 TPM, Week 8 placebo, Week 12 TPM, and Week 12 placebo groups, respectively. Among them, eight significantly enriched KEGG pathways with FDRs $<0.05$ at either time point or FDRs $<0.10$ at both time points were shared exclusively by the Week 8 and Week 12 TPM groups (Table 3). Comparing the pathways detected by Onto-tools with those detected by IPA, we found three were shared: synaptic long-term potentiation, Fc epsilon RI signaling, and natural killer-cell signaling. In contrast, no significantly enriched KEGG pathways were shared by the Week 8 and Week 12 placebo groups, with FDRs $<0.10$ at both time points. Again, although 81, 64, 60, and 65 pathways were detected for the Week 8 TPM, Week 8 placebo, Week 12 TPM, and Week 12 placebo groups, after Bonferroni correction, only 19, 5, 3, and 5 pathways remained significant. Furthermore, only two pathways (i.e., MAPK signaling and T-cell receptor signaling) were shared exclusively by the Week 8 and Week 12 TPM groups, and no pathways were shared by the Week 8 and Week 12 placebo groups.

Combining the results of IPA and Onto-Tools PathwayExpress, at the nominal $\mathrm{P}$ values $<0.05$ and further restricting by FDRs $<0.05$ at either time point or $<0.10$ at both, a total of 27 pathways were identified (see Table 3). These pathways are involved in a spectrum of physiological functions: some are associated mainly with signal transduction (Fc epsilon RI signaling, LPSstimulated MAPK signaling, p38 MAPK signaling, and SAPK/JNK signaling), whereas others are related to cardiovascular function (cardiac hypertrophy signaling, and renin-angiotensin signaling), and inflammation/ immune function (B-cell activating-factor signaling, CCR3 signaling in eosinophils, CCR5 signaling in macrophages, chemokine signaling, CXCR4 signaling, epithelial cell signaling in Helicobacter pylori infection, natural killer cell signaling, and role of PKR in interferon induction and antiviral response).

The essential pathways related to neuronal function/ synaptic plasticity include alpha-adrenergic signaling, ephrin receptor signaling, ErbB signaling, FGF signaling, GnRH signaling, mTOR signaling, neurotrophin/TRK signaling, and synaptic long-term potentiation. The genes in the synaptic long-term potentiation pathway that were changed by TPM at Week 8 and Week 12 are depicted in Figure 1.

\section{Discussion}

The current study is the first genome-wide expression investigation into the effects of TPM for the treatment of METH dependence. By profiling genome-wide expression patterns in human white blood cells from METHdependent subjects who received either oral TPM or 
Table 1 A list of 48 representative genes significantly up-regulated in week 8 topiramate group ${ }^{a}$

\begin{tabular}{|c|c|}
\hline Gene symbol & Gene name \\
\hline \multicolumn{2}{|c|}{ Cell adhesion/Motion } \\
\hline CD164 & CD164 molecule, sialomucin \\
\hline ITGA4 & Integrin, alpha 4 (antigen CD49D, alpha 4 subunit of VLA-4 receptor) \\
\hline ITGB1 & $\begin{array}{l}\text { Integrin, beta } 1 \text { (fibronectin receptor, beta polypeptide, antigen CD29 includes MDF2, } \\
\text { MSK12) }\end{array}$ \\
\hline SCYL2 & SCY1-like 2 (S. cerevisiae) \\
\hline \multicolumn{2}{|c|}{ Synaptic plasticity and nervous system development/function } \\
\hline DLG1 & Discs, large homolog 1 (Drosophila) \\
\hline GDI2 & GDP dissociation inhibitor 2 \\
\hline HIF1A & Hypoxia-inducible factor 1, alpha subunit (basic helix-loop-helix transcription factor) \\
\hline SCFD1 & Sec1 family domain containing 1 \\
\hline SNAP23 & Synaptosomal-associated protein, $23 \mathrm{kDa}$ \\
\hline TRAK2 & Trafficking protein, kinesin binding 2 \\
\hline ZFR & Zinc finger RNA binding protein \\
\hline
\end{tabular}

\section{Signal transduction}

\begin{tabular}{|c|c|}
\hline AKAP11 & A kinase (PRKA) anchor protein 11 \\
\hline CCNYL1 & Cyclin Y-like 1 \\
\hline ERBB2IP & Erbb2 interacting protein \\
\hline FGFR1OP2 & FGFR1 oncogene partner 2 \\
\hline MAPKIIP1L & Mitogen-activated protein kinase 1 interacting protein 1 -like \\
\hline PIK3AP1 & Phosphoinositide-3-kinase adaptor protein 1 \\
\hline PIK3R1 & Phosphoinositide-3-kinase, regulatory subunit 1 (alpha) \\
\hline PIP5K3 & Phosphatidylinositol-3-phosphate/phosphatidylinositol 5-kinase, type III \\
\hline PTEN & Phosphatase and tensin homolog \\
\hline RABEP1 & Rabaptin, RAB GTPase binding effector protein 1 \\
\hline RAP2A & RAP2A, member of RAS oncogene family \\
\hline RAP2C & RAP2C, member of RAS oncogene family \\
\hline SKAP2 & Src kinase associated phosphoprotein 2 \\
\hline SOS2 & Son of sevenless homolog 2 (Drosophila) \\
\hline TGFBR2 & Transforming growth factor, beta receptor II (70/80kDa) \\
\hline TOB1 & Transducer of ERBB2, 1 \\
\hline ZFAND6 & Zinc finger, AN1-type domain 6 \\
\hline \multicolumn{2}{|c|}{ Ubiquitination/Intracellular protein transport } \\
\hline CUL5 & Cullin 5 \\
\hline FBXL5 & F-box and leucine-rich repeat protein 5 \\
\hline FBXO28 & F-box protein 28 \\
\hline PCNP & PEST proteolytic signal containing nuclear protein \\
\hline PSMD12 & Proteasome (prosome, macropain) $26 \mathrm{~S}$ subunit, non-ATPase, 12 \\
\hline RNF11 & Ring finger protein 11 \\
\hline RNF149 & Ring finger protein 149 \\
\hline SEC62 & SEC62 homolog (S. cerevisiae) \\
\hline SMURF2 & SMAD specific E3 ubiquitin protein ligase 2 \\
\hline SRP54 & Signal recognition particle $54 \mathrm{kDa}$ \\
\hline
\end{tabular}

\begin{tabular}{|c|c|c|}
\hline Week 8 TPN & & \\
\hline$\overline{\mathrm{FC}} \quad \mathrm{SD}^{\mathrm{b}}$ & P Value ${ }^{c}$ & FDR $^{d}$ \\
\hline
\end{tabular}

$2.670 .38 \quad 1.0010^{-6} \quad 5.0710^{-5}$

$2.24 \quad 0.27 \quad 4.0010^{-6} \quad 1.3110^{-4}$

$2.200 .25 \quad 1.1010^{-5} \quad 2.6410^{-4}$

$2.450 .30 \quad 4.0010^{-6} \quad 1.3110^{-4}$

$1.660 .12 \quad 2.0010^{-6} \quad 8.2210^{-5}$

$1.630 .09<1.0010^{-6}<1.0010^{-5}$

$2.220 .26 \quad 4.0010^{-6} \quad 1.3110^{-4}$

$\begin{array}{lllllll}1.63 & 0.12 & 3.0010^{-6} & 1.0910^{-4}\end{array}$

$1.950 .19 \quad 2.0010^{-6} \quad 8.2210^{-5}$

$1.440 .07<1.0010^{-6}<1.0010^{-5}$

$2.140 .22 \quad 1.0010^{-6} \quad 5.0710^{-5}$

$2.230 .29 \quad 1.1010^{-5} \quad 2.6010^{-4}$

$\begin{array}{llllll}1.62 & 0.10 \quad 3.0010^{-6} & 1.0910^{-4}\end{array}$

$2.280 .23<1.0010^{-6}<1.0010^{-5}$

$\begin{array}{llllll}1.57 & 0.11 \quad 4.0010^{-6} & 1.31 & 10^{-4}\end{array}$

$1.390 .06<1.0010^{-6}<1.0010^{-5}$

$1.700 .14 \quad 5.0010^{-6} \quad 1.5410^{-4}$

$2.040 .23 \quad 7.0010^{-6} \quad 1.9210^{-4}$

$\begin{array}{lllllll}1.95 & 0.20 & 1.0010^{-5} & 2.5310^{-4}\end{array}$

$2.010 .10<1.0010 \quad-6<1.0010^{-5}$

$\begin{array}{llllll}1.42 & 0.08 & 5.0010^{-6} & 1.5410^{-4}\end{array}$

$\begin{array}{lllllll}1.75 & 0.15 & 8.0010^{-6} & 2.1310^{-4}\end{array}$

$\begin{array}{lllllll}1.84 & 0.16 & 3.00 & 10 & -6 & 1.09 & 10^{-4}\end{array}$

$1.760 .15 \quad 5.0010^{-6} \quad 1.5410^{-4}$

$2.510 .25<1.0010^{-6}<1.0010^{-5}$

$1.490 .09 \quad 8.0010^{-6} \quad 2.1310^{-4}$

$2.28 \quad 0.27 \quad 1.0010^{-6} \quad 5.07 \quad 10^{-5}$

$2.250 .20<1.0010^{-6}<1.0010^{-5}$

$2.250 .29 \quad 6.0010^{-6} \quad 1.7210^{-4}$

$1.690 .09<1.0010^{-6}<1.0010^{-5}$

$1.450 .08 \quad 5.0010^{-6} \quad 1.5410^{-4}$

$2.540 .35 \quad 3.0010^{-6} \quad 1.0910^{-4}$

$1.770 .12<1.0010^{-6}<1.0010^{-5}$

$3.290 .39<1.0010^{-6}<1.0010^{-5}$

$\begin{array}{lllllll}1.51 & 0.10 \quad 8.00 \quad 10 & -6 & 2.1310^{-4}\end{array}$

$1.690 .12<1.0010^{-6}<1.0010^{-5}$

$1.640 .10<1.0010^{-6}<1.0010^{-5}$

$1.560 .10 \quad 3.0010^{-6} \quad 1.0910^{-4}$ 
Table 1 A list of 48 representative genes significantly up-regulated in week 8 topiramate group ${ }^{\mathrm{a}}$ (Continued)

\begin{tabular}{|c|c|c|c|c|c|}
\hline UBE2D1 & Ubiquitin-conjugating enzyme E2D 1 (UBC4/5 homolog, yeast) & 2.410 .30 & 2.0010 & -6 & $8.2210^{-5}$ \\
\hline XPO1 & Exportin 1 (CRM1 homolog, yeast) & 1.980 .18 & $<1.0010$ & -6 & $<1.0010^{-5}$ \\
\hline YME1L1 & YME1-like 1 (S. cerevisiae) & 1.690 .11 & $<1.0010$ & -6 & $<1.0010^{-5}$ \\
\hline \multicolumn{6}{|c|}{ Mitochondrial function/Metabolism and energy pathways } \\
\hline ATP8A1 & ATPase, aminophospholipid transporter (APLT), class I, type 8A, member 1 & 2.110 .24 & 9.0010 & -6 & $2.3810^{-4}$ \\
\hline GALNT7 & $\begin{array}{l}\text { UDP-N-acetyl-alpha-D-galactosamine:polypeptide N-acetylgalactosaminyltransferase } 7 \\
\text { (GalNAc-T7) }\end{array}$ & 1.870 .17 & 3.0010 & -6 & $1.0910^{-4}$ \\
\hline MAN1A1 & Mannosidase, alpha, class 1A, member 1 & 2.260 .28 & 6.0010 & -6 & $1.7210^{-4}$ \\
\hline NUDT5 & Nudix (nucleoside diphosphate linked moiety X)-type motif 5 & 1.340 .04 & $<1.0010$ & -6 & $<1.0010^{-5}$ \\
\hline PGK1 & Phosphoglycerate kinase 1 & 1.350 .06 & 6.0010 & -6 & $1.7210^{-4}$ \\
\hline SLC25A46 & Solute carrier family 25 , member 46 & 2.200 .25 & 3.0010 & -6 & $1.0910^{-4}$ \\
\hline TXNL1 & Thioredoxin-like 1 & 1.490 .08 & 1.0010 & -6 & $5.0710^{-5}$ \\
\hline
\end{tabular}

placebo, we identified various number of genes that are differentially expressed between responders and nonresponders in the TPM-treated and placebo control groups. Further clustering of these altered genes according to their function revealed the significantly enriched pathways governing neuroplasticity and neurotoxicity/ neurodegeneration (see Figure 2). Given the primary purpose of this clinical trial, in this discussion, we focus primarily on how TPM may regulate molecular pathways of synaptic plasticity underlying METH s reward and reinforcing effects that influence abstinence.

Exposure to drugs of abuse triggers various gene expression changes resulting in complex neural adaptations that determine the addictive properties of abusive drugs [27]. Among these changes, modifications in long-term synaptic potentiation $(L T P)$ of neuroplasticity are fundamental in instilling reward and reinforcing the drug effects [28]. With evidence from decades of molecular research, it is established that METH alters LTP through activation of dopamine or glutamate surface receptors or both [29] that are linked to the intracellular signal transduction extracellularsignal-regulated-kinase (ERK) pathway. Among the surface neurotransmitter receptors regulating this pathway, the only receptor gene we found to be differentially expressed in the responders and non-responders to TPM was ionotropic glutamate receptor $\mathrm{N}$-methyl D-aspartate-associated protein 1 (GRINA). This protein is a subtype of $\mathrm{N}$-methyl D-aspartate (NMDA) receptors that are antagonized by TPM $[30,31]$ and activated by METH $[32,33]$. In the TPM responder group, GRINA was down-regulated at Week 8, implying fewer NMDA receptors at the synapse. Although expression of none of the other primary target genes of TPM (such as $\mathrm{GABA}_{\mathrm{A}}$ and AMPA/kainate glutamate receptors) was altered by TPM, three genes coding for membrane trafficking proteins (DLG1, SNAP23, and $T R A K 2$ ) associated with these receptors were up-regulated in TPM responders compared with non-responders and placebo-treated subjects. The DLG1 gene encodes a synaptic scaffolding protein (also known as synapse-associated protein 97) involved in synapse formation [34] and trafficking of AMPA [35,36], kainate [37], and NMDA [38,39] glutamate receptors. SNAP23 is a scaffolding protein that aids in stabilizing NMDA receptors at the neuronal surface [40]. The TRAK2 product is involved in $\mathrm{GABA}_{\mathrm{B}}$-receptor trafficking [41]. In rat neocortex, DLG1 mRNA is upregulated by the NMDA antagonist phencyclidine but not by METH [42]. Considering these factors, it is possible that TPM-associated alterations in the expression of AMPA, kainite, and $\mathrm{GABA}_{\mathrm{A}}$ receptors at the neuronal surface are more likely to be further governed by posttranscriptional modifications such as receptor phosphorylation and trafficking to and from the synaptic membrane, rather than through alterations in their transcription.

Once METH activates its neural receptors, they activate ERK via the upstream cytoplasmic regulators of the ERK pathway; activated ERK translocates from the cytoplasm to the nucleus and phosphorylates cAMP response element binding protein (CREB) [27] to facilitate METH-induced gene expression, serving as the mediator between the nucleus and the target receptors of METH at the neuronal surface [43]. The drug might activate the ERK pathway via either up-regulation of gene transcription, posttranscriptional activation of protein phosphorylation, or both. In the present study, expression of several genes of the ERK pathway was down-regulated in responders at Week 8 of TPM treatment compared with non-responders and the placebo-treated subjects (see Figure 1A), suggesting a reversal of METH-induced up-regulation of ERK 
Table 2 A List of 45 representative genes significantly down-regulated in week 8 topiramate group ${ }^{\mathrm{a}}$

\begin{tabular}{|c|c|c|c|c|c|}
\hline \multirow[t]{2}{*}{ Gene symbol } & \multirow[t]{2}{*}{ Gene name } & \multicolumn{4}{|c|}{ Week 8 TPM } \\
\hline & & $\overline{\mathrm{FC}} \mathrm{SD}^{\mathrm{b}}$ & \multicolumn{2}{|c|}{ P Value $^{c}$} & FDR $^{d}$ \\
\hline \multicolumn{6}{|c|}{ Cell adhesion/Motion } \\
\hline$C D C 2 L 2$ & Cell division cycle 2-like 2 & -1.390 .07 & 1.1010 & -5 & $2.6410^{-4}$ \\
\hline CDC42EP2 & CDC42 effector protein (Rho GTPase binding) 2 & -2.010 .19 & 1.0010 & -6 & $5.0710^{-5}$ \\
\hline EMILIN2 & Elastin microfibril interfacer 2 & -1.410 .05 & $<1.0010$ & -6 & $<1.0010^{-5}$ \\
\hline JAK3 & Janus kinase 3 (a protein tyrosine kinase, leukocyte) & -1.680 .11 & 1.0010 & -6 & $5.0710^{-5}$ \\
\hline TUBB2C & Tubulin, beta $2 \mathrm{C}$ & -1.390 .06 & 2.0010 & -6 & $8.2210^{-5}$ \\
\hline \multicolumn{6}{|c|}{ Nervous system development and function/synaptic plasticity } \\
\hline ADAT1 & Adenosine deaminase, tRNA-specific 1 & -1.610 .08 & $<1.0010$ & -6 & $<1.0010^{-5}$ \\
\hline CIRBP & Cold inducible RNA binding protein & -1.740 .13 & 1.0010 & -6 & $5.0710^{-5}$ \\
\hline DGCR14 & 3-phosphoinositide dependent protein kinase-1 & -1.450 .04 & $<1.0010$ & -6 & $<1.0010^{-5}$ \\
\hline FKBP4 & FK506 binding protein 4, $59 \mathrm{kDa}$ & -1.490 .10 & 6.0010 & -6 & $1.7210^{-4}$ \\
\hline NAPA & $\mathrm{N}$-ethylmaleimide-sensitive factor attachment protein, alpha & -2.040 .21 & 1.0010 & -6 & $5.0710^{-5}$ \\
\hline$P 2 R \times 1$ & Purinergic receptor P2X, ligand-gated ion channel, 1 & -1.720 .13 & 2.0010 & -6 & $8.2210^{-5}$ \\
\hline PRKACA & Solute carrier family 1 (glial high affinity glutamate transporter), member 3 & -1.690 .15 & 1.1010 & -5 & $2.6410^{-4}$ \\
\hline SHC1 & SHC (Src homology 2 domain containing) transforming protein 1 & -1.230 .04 & 3.0010 & -6 & $1.0910^{-4}$ \\
\hline TRIM8 & Tripartite motif-containing 8 & -1.450 .06 & 4.0010 & -6 & $1.3110^{-4}$ \\
\hline \multicolumn{6}{|c|}{ Signaling transduction } \\
\hline ARHGEF2 & Rho/rac guanine nucleotide exchange factor (GEF) 2 & -1.620 .11 & 2.0010 & -6 & $8.2210^{-5}$ \\
\hline$B C R$ & Breakpoint cluster region & -1.430 .06 & $<1.0010$ & -6 & $<1.0010^{-5}$ \\
\hline GRINA & Glutamate receptor, ionotropic, N-methyl D-aspartate-associated protein 1 & -2.490 .28 & $<1.0010$ & -6 & $<1.0010^{-5}$ \\
\hline LIMK2 & LIM domain kinase 2 & -3.050 .44 & 4.0010 & -6 & $1.3110^{-4}$ \\
\hline PHPT1 & Phosphohistidine phosphatase 1 & -1.330 .06 & 7.0010 & -6 & $1.9210^{-4}$ \\
\hline PLCB2 & Phospholipase C, beta 2 & -1.930 .13 & $<1.0010$ & -6 & $<1.0010^{-5}$ \\
\hline RHOT2 & Ras homolog gene family, member T2 & -1.460 .05 & $<1.0010$ & -6 & $<1.0010^{-5}$ \\
\hline \multicolumn{6}{|c|}{ Ubiquitination/Intracellular protein transport } \\
\hline$A P 2 A 1$ & Adaptor-related protein complex 2, alpha 1 subunit & -2.040 .20 & 1.1010 & -5 & $2.6410^{-4}$ \\
\hline NPEPL1 & Aminopeptidase-like 1 & -1.260 .03 & $<1.0010$ & -6 & $<1.0010^{-5}$ \\
\hline SHARPIN & SHANK-associated RH domain interactor & -2.130 .26 & 1.0010 & -5 & $2.5310^{-4}$ \\
\hline TRAPPC5 & Trafficking protein particle complex 5 & -1.580 .11 & 6.0010 & -6 & $1.7210^{-4}$ \\
\hline UBE2M & Ubiquitin-conjugating enzyme E2M (UBC12 homolog, yeast) & -1.700 .12 & 1.0010 & -6 & $5.0710^{-5}$ \\
\hline UBXN6 & UBX domain protein 6 & -2.400 .29 & 2.0010 & -6 & $8.2210^{-5}$ \\
\hline USP4 & Ubiquitin specific peptidase 4 (proto-oncogene) & -1.460 .06 & 2.0010 & -6 & $8.2210^{-5}$ \\
\hline WBP2 & WW domain binding protein 2 & -1.850 .18 & 4.0010 & -6 & $1.3110^{-4}$ \\
\hline \multicolumn{6}{|c|}{ Mitochondrial function/metabolism and energy pathways } \\
\hline ATAD3B & ATPase family, AAA domain containing 3B & -1.470 .07 & $<1.0010$ & -6 & $<1.0010^{-5}$ \\
\hline B4GALT3 & UDP-Gal:betaGIcNAc beta 1,4- galactosyltransferase, polypeptide 3 & -1.260 .04 & 1.0010 & -6 & $5.0710^{-5}$ \\
\hline COASY & Coenzyme A synthase & -1.290 .06 & 1.2010 & -5 & $2.7910^{-4}$ \\
\hline COX5B & Cytochrome c oxidase subunit Vb & -1.440 .09 & 1.2010 & -5 & $2.7910^{-4}$ \\
\hline GANAB & Glucosidase, alpha; neutral AB & -1.630 .08 & $<1.0010$ & -6 & $<1.0010^{-5}$ \\
\hline MRPL37 & Mitochondrial ribosomal protein $\mathrm{L} 37$ & -1.300 .04 & $<1.0010$ & -6 & $<1.0010^{-5}$ \\
\hline NAGK & $\mathrm{N}$-acetylglucosamine kinase & -1.300 .05 & 4.0010 & -6 & $1.3110^{-4}$ \\
\hline NDUFV3 & $\mathrm{NADH}$ dehydrogenase (ubiquinone) flavoprotein 3, $10 \mathrm{kDa}$ & -1.630 .08 & $<1.0010$ & -6 & $<1.0010^{-5}$ \\
\hline
\end{tabular}


Table 2 A List of 45 representative genes significantly down-regulated in week 8 topiramate group ${ }^{a}$ (Continued)

\begin{tabular}{|c|c|c|c|c|c|}
\hline PFKL & Phosphofructokinase, liver & -1.530 .10 & 3.0010 & -6 & $1.0910^{-4}$ \\
\hline UROD & Uroporphyrinogen decarboxylase & -1.350 .06 & 5.0010 & -6 & $1.5410^{-4}$ \\
\hline \multicolumn{6}{|c|}{ Immune system function } \\
\hline $\mathrm{CISH}$ & Cytokine inducible $\mathrm{SH}$-containing protein & -1.340 .05 & 1.0010 & -6 & $5.0710^{-5}$ \\
\hline$H L A-E$ & Major histocompatibility complex, class I, E & -1.250 .04 & $<1.0010$ & -6 & $<1.0010^{-5}$ \\
\hline JMJD3 & Jumonji domain containing 3, histone lysine demethylase & -2.030 .16 & $<1.0010$ & -6 & $<1.0010^{-5}$ \\
\hline MSRB2 & Methionine sulfoxide reductase B2 & -1.680 .13 & 2.0010 & -6 & $8.2210^{-5}$ \\
\hline OAS1 & 2',5'-oligoadenylate synthetase 1, 40/46 kDa & -1.840 .15 & 1.0010 & -6 & $5.0710^{-5}$ \\
\hline TAPBP & TAP binding protein (tapasin) & -1.600 .06 & $<1.0010$ & -6 & $<1.0010^{-5}$ \\
\hline
\end{tabular}

${ }^{a}$ Genes are selected from a total of 62 down-regulated genes with Bonferroni-corrected $P$ Values $<0.05$ (i.e., $0.05 / 3698$ genes $=1.35$ ? $10^{-5}$ ).

${ }^{\mathrm{b}} \mathrm{FC}$, denoting fold change, is defined as the ratio of the expression values of Positive Responders over Negative Responders; SD, standard deviation.

'P Value was calculated using the ordinary Students $t$ test for each gene.

${ }^{d}$ FDR, denoting false discovery rate, was estimated by the Benjamini-Hochberg $(\mathrm{BH})$ method.

pathway genes. At Week 8, these TPM-related downregulated genes included ERK-1 (MAPK3) and its upstream regulators, protein kinase A (PRKACA), protein kinases $\mathrm{C}$ and $\mathrm{Z}$ (PRKCD and PRKCZ), Ras-related genes (ARHGEF2, RHOT2, and RRAS), and EP300, which encodes a transcriptional co-activator that forms a complex with CREB-binding protein (CBP). By Week 12, besides $E P 300$, the transcription factor CREB gene CREB5 expression was down-regulated in TPM responders.

Given these findings, it is reasonable to hypothesize that (1) reversal of ERK and CREB over-expression results in blocking of METH-dependent transcription activity and consequently disruption of METH-induced LTP and (2) non-responders may harbor variants that affect expression of genes that are down-regulated in TPM responders. These possibilities have gained support from several lines of evidence reported by other investigators. For example, Narita et al. [29] demonstrated that blockade of protein kinase C (PKC) abolishes behavioral sensitization to METH. Human laboratory studies have indicated a partial inhibition of METHs reinforcing effects by TPM at the same dosage used in the current study [23]. More importantly, our findings corroborate the concept that TPM would be a possible treatment for METH addiction through facilitating the inhibitory effects of GABA and blocking glutamate excitatory effects on dopamine neurons $[22,23]$.

Apart from pathways governing neural plasticity, the functional category with the largest number of affected pathways was in immune function (see Table 3). Data on TPMs effects on immune mediators is sparse, with a few studies emerging recently. Among the ten immune function-related pathways detected in the current study, only the T-cell receptor signaling pathway has been reported previously to be regulated by TPM [44]. A common feature of all these pathways and the pathways governing neuroplasticity is their use of the mitogenactivated-protein-kinase (MAPK) pathway as the central component. As this is not the primary focus of this report, a detailed discussion of those immune-related pathways will not be provided here.

The reliability of our findings is strengthened by a number of aspects of our study design: First, the present study included both a positive (TPM non-responders) and a negative (placebo) control group. Inclusion of a placebo group provided us with a reference necessary for the exploration of gene expression alterations induced specifically by TPM rather than by the absence or reduction of METH use or any other non-specific factors. For example, EP300, a member of the CREB gene family, was down-regulated in both the Weeks 8 and 12 TPM responder and the Week 12 placebo responder groups, suggesting that the regulatory effect of the gene is not specific to TPM, whereas CREB5, discussed above, was down-regulated only in Week 12 TPM responders, suggesting a TPM-specific effect. Further, the inclusion of a positive control group aided us in identifying genes and pathways associated with METH abstinence, which was the primary outcome of this clinical study. Second, we analyzed expression data from three time points, namely, the baseline (prior to starting TPM treatment) and Weeks 8 and 12 for each individual. This approach allowed us to correct for any confounding effects that might be caused by significant individual gene expression differences among subjects at baseline, by normalizing the extent of expression at Weeks 8 and 12 with the patients own baseline expression and increasing the reliability of the findings by utilizing Week 12 expression patterns to confirm those that occurred at Week 8 . The third main strength of the present study is that the dose of TPM administered throughout the treatment period was well within the drug s therapeutic range [22,23], and therefore, we can confidently conclude that the TPMdependent expression alterations we detected were not related to TPMs toxic effects, but rather to its therapeutic effects. Finally, we believe that, with the level of 
Table 3 Significantly enriched pathways detected exclusively in week 8 and week 12 topiramate groups $(n=27)^{a}$

\begin{tabular}{|c|c|c|c|c|c|c|}
\hline \multirow[b]{2}{*}{ Pathway name ${ }^{\text {b }}$} & \multicolumn{3}{|c|}{ Week 8 TPM } & \multicolumn{3}{|c|}{ Week 12 TPM } \\
\hline & No. genes & P Value & $\mathrm{FDR}^{\mathrm{C}}$ & No. genes & P Value & FDR $^{c}$ \\
\hline \multicolumn{7}{|l|}{ Neuronal function/Synaptic plasticity $(n=8)$} \\
\hline Alpha-adrenergic signaling ${ }^{\mathrm{a}}$ & 17 & 0.025 & 0.042 & 10 & 0.0036 & 0.029 \\
\hline Ephrin receptor signaling ${ }^{a}$ & 36 & $1.7010^{-4}$ & $7.1810^{-4}$ & 17 & $5.7510^{-4}$ & 0.0095 \\
\hline ErbB signaling pathway ${ }^{b}$ & 18 & 0.0026 & 0.0081 & 8 & 0.0078 & 0.035 \\
\hline FGF signaling ${ }^{a}$ & 18 & 0.0040 & 0.0086 & 8 & 0.017 & 0.074 \\
\hline GnRH signaling pathway ${ }^{\mathrm{b}}$ & 20 & 0.0017 & 0.0060 & 11 & 0.0012 & 0.013 \\
\hline mTOR signaling pathway ${ }^{\mathrm{b}}$ & 15 & $4.4710^{-5}$ & $3.7810^{-4}$ & 5 & 0.033 & 0.090 \\
\hline Neurotrophin/TRK signaling ${ }^{a}$ & 17 & $9.3310^{-4}$ & 0.0027 & 7 & 0.017 & 0.074 \\
\hline Synaptic long term Potentiation ${ }^{\mathrm{a}, \mathrm{b}}$ & 29 & $6.17 \quad 10^{-6}$ & $7.44 \quad 10^{-5}$ & 10 & 0.012 & 0.058 \\
\hline \multicolumn{7}{|l|}{ Signal transduction $(n=6)$} \\
\hline Adipocytokine signaling ${ }^{b}$ & 14 & 0.0070 & 0.017 & 9 & $9.3010^{-4}$ & 0.013 \\
\hline Fc Epsilon RI Signaling ${ }^{a, b}$ & 24 & $1.51 \quad 10^{-4}$ & $6.73 \quad 10^{-4}$ & 11 & 0.0018 & 0.021 \\
\hline LPS-stimulated MAPK signaling $^{\text {a }}$ & 23 & $2.7510^{-6}$ & $4.6510^{-5}$ & 9 & 0.0025 & 0.024 \\
\hline NF-KB signaling ${ }^{a}$ & 33 & $3.0210^{-5}$ & $2.0410^{-4}$ & 14 & 0.0016 & 0.021 \\
\hline p38 MAPK signaling ${ }^{a}$ & 20 & 0.0037 & 0.0082 & 9 & 0.014 & 0.062 \\
\hline SAPKJJNK signaling ${ }^{a}$ & 18 & 0.011 & 0.021 & 14 & $1.3510^{-5}$ & $5.5610^{-}$ \\
\hline \multicolumn{7}{|l|}{ Cardiovascular function $(n=2)$} \\
\hline Cardiac hypertrophy signaling $^{a}$ & 42 & $2.4510^{-4}$ & $9.2210^{-4}$ & 16 & 0.013 & 0.062 \\
\hline Renin-angiotensin signaling ${ }^{a}$ & 27 & $3.5510^{-5}$ & $2.2410^{-4}$ & 14 & $8.9110^{-5}$ & 0.0025 \\
\hline \multicolumn{7}{|l|}{ Inflammation/Immune function $(n=8)$} \\
\hline B cell activating factor signaling ${ }^{a}$ & 10 & 0.013 & 0.023 & 5 & 0.022 & 0.090 \\
\hline CCR3 signaling in eosinophils ${ }^{a}$ & 24 & 0.0013 & 0.0035 & 13 & $5.2510^{-4}$ & 0.0095 \\
\hline CCR5 signaling in macrophages ${ }^{a}$ & 13 & 0.030 & 0.048 & 11 & $5.6210^{-5}$ & 0.0019 \\
\hline Chemokine signaling $^{a}$ & 21 & $4.3710^{-5}$ & $2.5410^{-4}$ & 8 & 0.0096 & 0.049 \\
\hline CXCR4 signaling ${ }^{a}$ & 28 & 0.0065 & 0.014 & 11 & 0.045 & 0.14 \\
\hline Epithelial cell signaling in Helicobacter pylori infection ${ }^{\text {b }}$ & 16 & 0.0011 & 0.0048 & 8 & 0.0063 & 0.031 \\
\hline Natural killer cell signaling $a, b$ & 26 & $1.15 \quad 10^{-4}$ & $5.54 \quad 10^{-4}$ & 12 & 0.0013 & 0.019 \\
\hline Role of PKR in Interferon Induction and Antiviral Response ${ }^{a}$ & 11 & 0.0051 & 0.011 & 5 & 0.025 & 0.094 \\
\hline \multicolumn{7}{|l|}{ Other $(n=3)$} \\
\hline Hepatic cholestasis ${ }^{a}$ & 24 & 0.014 & 0.026 & 12 & 0.0076 & 0.042 \\
\hline Macropinocytosis ${ }^{a}$ & 17 & $6.4610^{-4}$ & 0.0021 & 8 & 0.0043 & 0.034 \\
\hline Xenobiotic metabolism signaling ${ }^{a}$ & 37 & 0.044 & 0.065 & 19 & 0.0053 & 0.036 \\
\hline
\end{tabular}

angenuity Pathways Knowledge Base Pathways with Number of Genes $\geq 3$, P Values $<0.05$, FDRs $<0.05$ at either Week 8 or Week 12 and FDRs $<0.10$ at both were selected by Ingenuity Pathway Analysis (IPA) URL: http://www.ingenuity.com/.

${ }^{b}$ Kyoto Encyclopedia of Genes and Genomes (KEGG) pathways with Number of Genes $\geq 3$ and Gamma P Values $<0.05$, and FDRs $<0.05$ at either Week 8 or Week 12 and FDRs $<0.10$ at both were selected by Onto-Tools URL: http://vortex.cs.wayne.edu/ontoexpress/. For pathways identified by both IPA and Onto-Tools (shown in italic), only IPA results were presented.

${ }^{\mathrm{C}} \mathrm{FDR}$, denoting false discovery rate, was estimated by the Benjamini-Hochberg (BH) method.

rigorousness of the clinical and statistical criteria employed in defining treatment responders and significantly altered genes and pathways, the chance that our findings are falsely positive is minimal.

However, this study is limited by several factors, of which the most notable is the small sample size for some comparison groups. Especially, the number of responders in the TPM and placebo groups were not balanced for either Week 8 or Week 12 ( 4 and 2 subjects for Weeks 8 and 12 in the placebo group vs. 5 and 6 subjects in TPM group for Weeks 8 and 12). However, these numbers are not distinctly smaller than those in other pharmacogenomic/expression studies published in the literature [45] and provided us with an $85 \%$ statistical power to draw conclusions about individual genes and pathways [46]. On the other hand, it could be argued that the imbalance in 


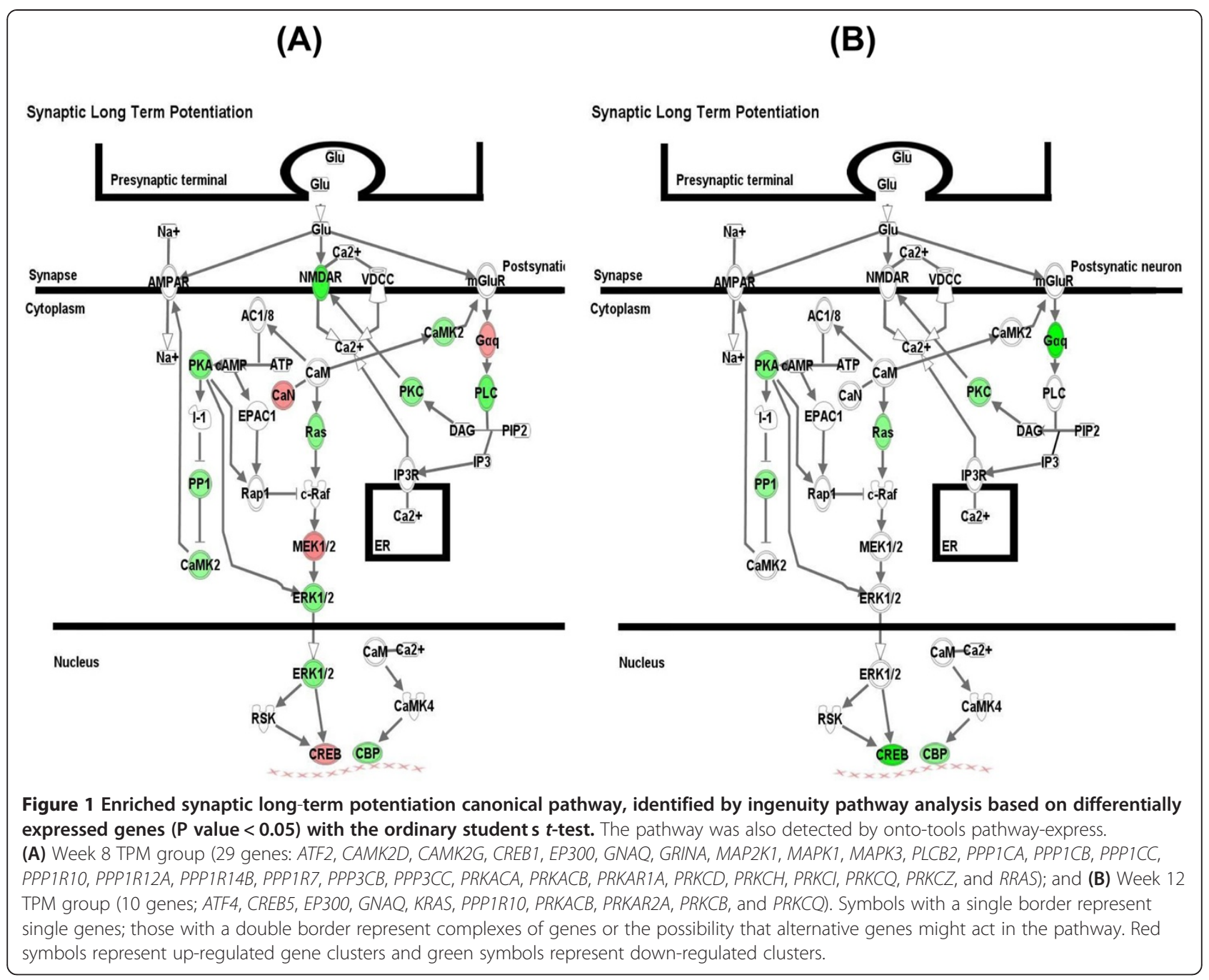

the number of responders in the two groups was attributable in part to weaker effects of the placebo in promoting abstinence compared with TPM. Because of the small samples, we did not consider covariate effects such as age, sex, and ethnicity in assessing single-gene effects. Although we believe the results obtained from such samples are reliable, extra attention should be paid in interpreting the expression pattern of single genes, especially those identified from the placebo groups. Another main limitation of our study is that we used a peripheral white blood cell model to study the gene expression alterations associated with neuronal functions. Peripheral blood is an easily accessible source of RNA for analysis of environmental exposure and disease conditions [47-49]. Circulating leukocytes can be used to infer gene expression in other tissues [50]. Indeed, constituents of blood maintain the balance of homeostasis, modulate immunity or inflammation, partake in stress signaling, and facilitate cellular communication in vascular-associated tissues, including those of the CNS [51]. Sullivan et al. [52] conducted a secondary data analysis of transcriptional profiling of 79 diverse human tissues and found that whole blood shared substantial gene expression similarities with multiple brain tissues such as the amygdala, caudate nucleus, prefrontal cortex, and whole brain (the median Spearman correlation coefficient for the group was 0.52), indicating that gene expression in whole blood can be a robust and valid surrogate for gene expression in the brain [52]. However, in another recent study, only weak correlation was detected between gene expression in the brain and that in blood samples [53]. Under such conditions, although the gene expression data from whole blood may provide useful information to infer the biological processes underlying the interaction of TPM and METH in the neuronal system, more direct evidence obtained from brain tissues is necessary in order to verify the findings reported in this study.

\section{Conclusions}

In summary, with application of rigorous clinical and statistical criteria, we demonstrated that TPM mitigates 


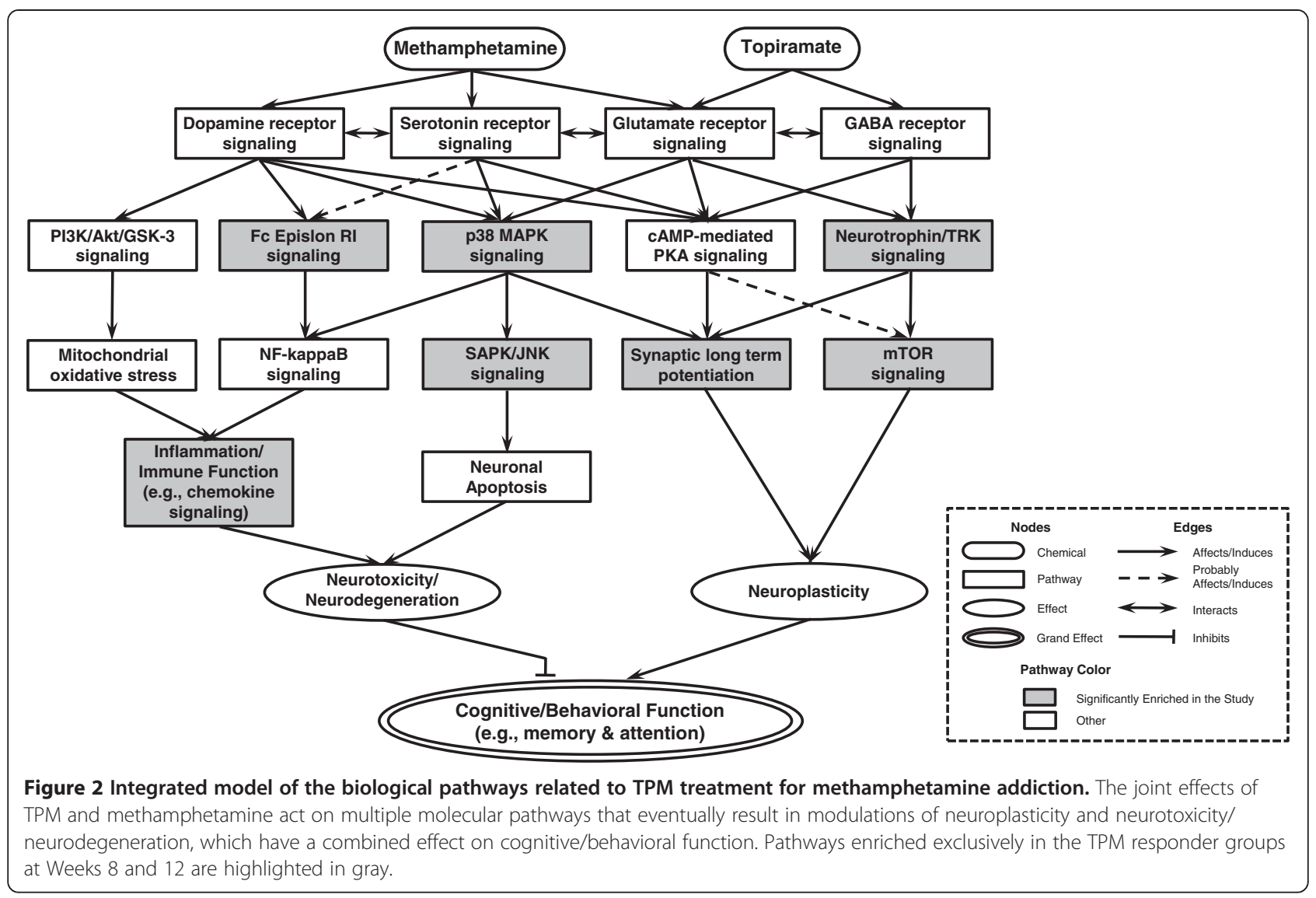

METH s reinforcing effects, possibly through reversal of some of the dysregulated genes in pathways governing synaptic plasticity to their normal state. Further studies are necessary to replicate these findings as well as to identify genetic variations that may have resulted in regulatory differences observed in TPM responders vs. non-responders. Identification of such molecular mechanisms will help greatly in developing efficacious medications for the treatment of METH dependence.

\section{Methods}

\section{Study design and blood sample collection}

This was a double-blind, multi-center, placebo-controlled, randomized, parallel-group study for METH-dependent outpatients [26]. Under the inter-agency agreement between the National Institute on Drug Abuse and the Veterans Affairs (VA) Cooperative Programs, eight medical centers participated. The sites Institutional Review Boards and the VA Human Rights Committee approved the protocol for and conduct of the study.

Subjects meeting the eligibility criteria after a 14-day screening period and a baseline assessment were randomized into equivalent-size groups for oral treatment with TPM or placebo daily for 91 days. There was a dose titration phase (Days 1 to 35 ) to a maximum tolerated dose of TPM not to exceed $200 \mathrm{mg} /$ day, a maintenance phase (Days 36 to 84), and a taper phase (Days 85 to 91). To continue in the study, subjects had to maintain a minimum daily dose of $50 \mathrm{mg}$. Blood samples were collected on Day 1 (considered the baseline) and at the end of Weeks 8 and 12 from every participant who consented to participate in the genetics/expression study. The rationale for using weeks 8 and 12 of TPM treatment in the genetic/expression study was that these two time points were in the middle of the maintenance phase of the maximum dose for each patient and the end of treatment, respectively. At the two time points, because the TPM dose given to each patient became relatively stable, this would reduce variability of drugs received among patients, thus likely increasing statistical power of identifying differentially expressed genes and pathways. All blood samples for this study were collected in PAXgeneTM blood tubes using standard phlebotomy technique.

\section{Primary efficacy outcome measure}

The primary efficacy outcome measure was METH use or non-use during each week of the entire period from weeks 1 to 12 . For each participant, urine samples were collected three times per week. A positive use week was 
defined as any week in which at least one of the urine tests was positive for METH and a negative use week as one in which all three tests were negative. The value was considered to be missing if no urine sample was collected. On the basis of the primary efficacy outcome measures for the entire trial period, each study participant in either the TPM or the placebo group was classified as either a positive or negative responder to the treatment, which was referred to as responder or nonresponder in this study. For example, a TPM responder at Week 8 means for this participant receiving TPM treatment no METH was detected in all the three urine samples for Week 8 (negative use week); whereas for a TPM non-responder, METH was detected in one or more urine samples. Our aim was to determine which genes were differentially expressed in the responders and non-responders of the TPM or placebo group during a given week. Because we collected blood samples from each participant at baseline and Weeks 8 and 12, we formed four analysis groups: Week 8 TPM, Week 8 placebo, Week 12 TPM, and Week 12 placebo, according to the positive or negative use information at Weeks 8 and 12, respectively. Because not all participants contributed blood samples at both time points, the final sample sizes were different for each group.

\section{RNA isolation and gene expression analysis}

Blood samples were collected at approximately the same time of day for each participant for all three time points to control for potential circadian rhythm effects on gene expression. Total RNA was extracted using the PAXgene Blood RNA Isolation Kit (Qiagen, Valencia, CA, USA). Genome-wide expression of each sample was assessed with a Human Genome U-133 Plus 2.0 array (Affymetrix Inc., Santa Clara, CA, USA) by Expression Analysis Inc. (Durham, NC). Briefly, the double-stranded cDNA was used in a T7 RNA polymerase in vitro transcription reaction (Ambion, Austin, TX, USA) containing biotin-labeled ribonucleotides CTP and UTP. The resulting labeled cRNAs were then hybridized to HGU133plus2.0 arrays.

\section{Quality control and bioinformatics analysis of array data}

Outlier array detection and quality assessment: In total, there were 212 HG-U133plus2.0 arrays from 99 study participants, which included 91 arrays at baseline, 65 at Week 8 , and 56 at Week 12. The 212 .CEL files generated by the Microarray Suite (MAS 5.0; Affymetrix) were converted into .DCP files using dChip 2008 software (http:// biosun1.harvard.edu/ cli/dchip_2008_05.exe). We used the $\%$ array outlier diagnostic metric to detect outlier arrays, defined as the percentage of outlier probe sets in one array [54]. If this percentage exceeded 5\%, the array was called an outlier. Three arrays at baseline were found to have a $\%$ array outlier metric $>5 \%$ and were excluded from further analysis. For quality assessment of the remaining 209 chips, the distributions of $\log _{2}$-transformed raw probe-level intensities were visualized by boxplots, and no anomalies were found (data not shown).

Data pre-processing and normalization: Data quality assessment was followed by data pre-processing and normalization with the Robust Multi-Array Average (RMA) algorithm [55], implemented in the RMA function in the Bioconductor Affy package [56]. The RMA is a statistical method comprising three procedures performing the following functions: (i) convolution background correction; (ii) probe-level quantile normalization; and (iii) median polish summarization for each probe set to estimate the $\log _{2}$ scale expression values. A matrix of expression values was computed for the 209 .CEL files. The expression values after normalization were similar across arrays.

Probe set filtering: The HG-U133plus2.0 array contains 54,675 oligonucleotide-based probe sets. However, not all of these sets correspond to well-defined genes. By using the latest Affymetrix annotation file (dated November 30, 2008), we found that a total of $33,752(61.73 \%)$ probe sets correspond to unique genes, whereas the remaining probe sets do not and were thus excluded from our statistical analysis. Furthermore, we implemented a series of filtering procedures to reduce the number of probe sets to be tested, which is summarized as follows: $(i)$ Filtering Absence call probe sets: We applied a Bioconductor package called Presence-Absence Calls with Negative Probesets (PANP) that uses Affymetrix-reported probe sets with no known hybridization partners. PANP uses a simple empirically derived approach to generate $\mathrm{P}$ values for thresholds to define presence/absence calls. The presence/absence calls and $\mathrm{P}$ values are returned as two matrices: Pcalls and Pvals, respectively. Probe sets with $<50 \%$ present calls among all arrays within each group were removed, which is considered restrictive [57,58], leaving $\sim 15,000$ probe sets for further analysis. (ii) Filtering biologically irrelevant genes and duplicate probe set $(s)$ for each selected gene: Among the $\sim 15,000$ probe sets, control sets of various housekeeping genes (e.g., $G A P D H$ ) and spiked-in controls (e.g., Ec-bioB, Ec-bioC, $E c-b i o D)$, as well as those genes that are not well defined or have unknown functions were removed. After removing duplicate probe set(s) for the same gene, such that only the probe set with the smallest test statistic was kept for each gene [59], about 7,500 genes remained. (iii) Filtering out genes with low fold changes (FCs): Genes with $\log _{2}$ (FC) $<0.67$ standard deviation (SD) away from the group mean (i.e., between the first and the third quartile assuming that $\log _{2}(\mathrm{FC})$ follows a normal distribution) were removed. After these sequential steps of filtering, about 3,500 genes were left for downstream statistical analyses 
for each group. A schematic diagram of the detailed data mining and analysis plan is shown in Figure 3.

\section{Statistical analysis to identify differentially expressed genes and pathways}

After data quality checking, pre-processing, normalization, and probe set filtering, we analyzed the microarray data at both the single-gene level (where one seeks to determine whether each gene is expressed differently under different conditions) and the pathway level (where one intends to determine if a biological pathway shows a different expression pattern under different conditions). Considering the individual variations at the baseline, we normalized each individuals Week 8 and Week 12 expression values by the corresponding baseline values prior to the identification of differentially expressed genes and biological pathways.

Single-gene analysis The primary goal of this step is to detect those genes with significantly different expressions in two comparison groups that cannot be ascribed to chance or natural variability [60]. The ordinary Students $t$-test, implemented by MATLAB (MathWorks, Natick, MA), was employed for testing differential expressions in a gene-by-gene manner. To correct for multiple testing, both Bonferroni correction and false discovery rate (FDR); i.e., the expected proportion of falsely rejected null

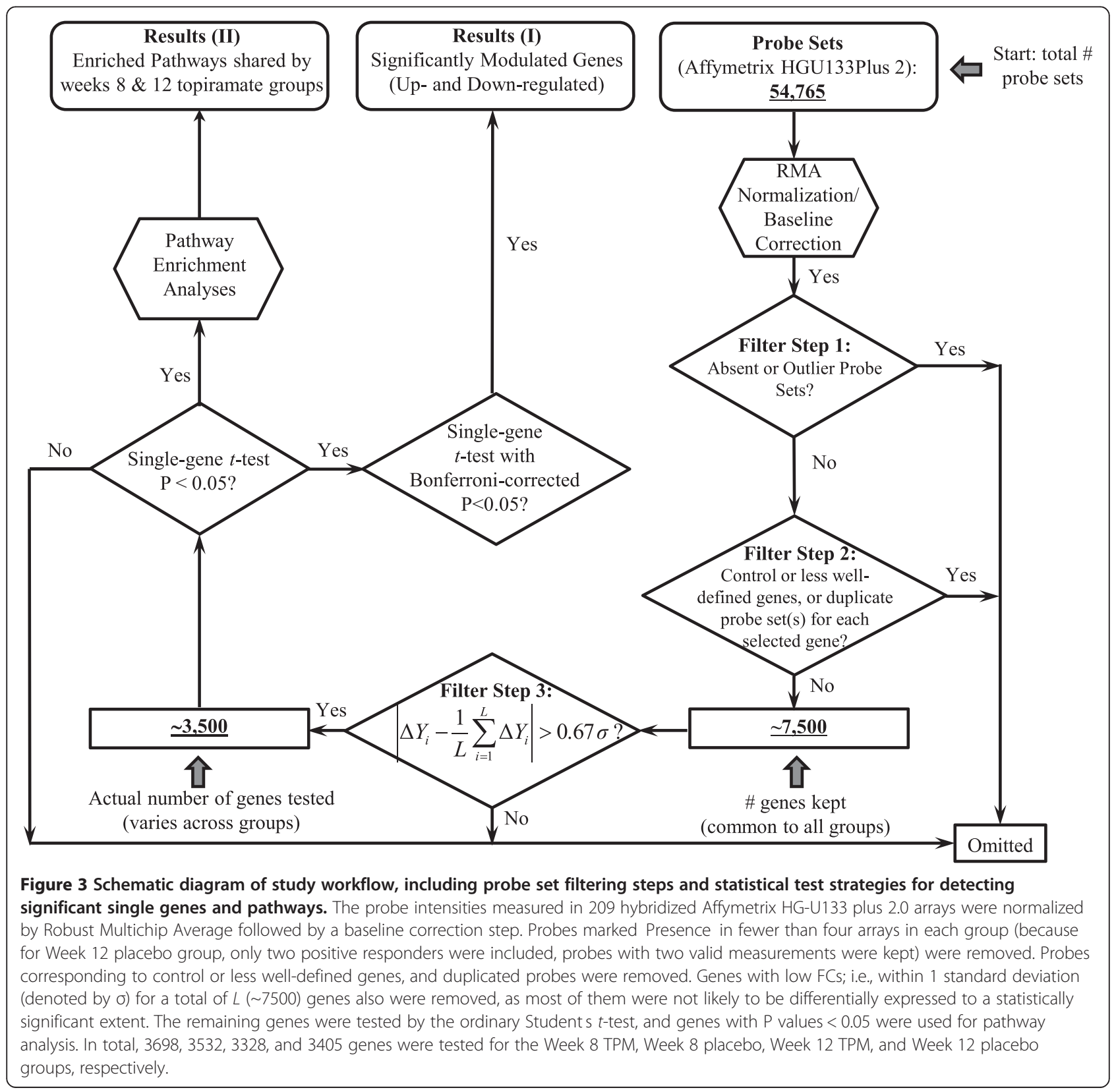


hypotheses among the rejected hypotheses, which was estimated by the Benjamini-Hochberg $(\mathrm{BH})$ procedure [61], were applied.

Pathway analysis Because gene expression is a wellcoordinated system, expressions of different genes generally are not independent. Pathway analysis can reduce the number of hypotheses to a more manageable number that directly addresses questions of biological interest. During the past few years, various bioinformatics tools have been developed for pathway analysis, although none has gained widespread acceptance [60]. Therefore, in the current study, significantly enriched pathways of differentially expressed genes were detected using the following bioinformatics tools:

Ingenuity Pathway Analysis (IPA) (http://www.ingenuity. com/) The IPA is a web-based bioinformatics tool [62]. A given set of input genes was associated with molecular networks based on their connectivities in the Ingenuity Pathways Knowledge Base. Fishers exact test was used to determine the probability that each biological function assigned to that data set was attributable to chance alone [63].

Onto-Tools Pathway-Express (http://vortex.cs.wayne.edu/ projects.htm) The Onto-Tools Pathway-Express [64,65] implements an innovative Impact Factor Analysis based on the Kyoto Encyclopedia of Genes and Genomes (KEGG) pathway database. Distinct from either OverRepresentation Analysis (ORA) or Gene Set Enrichment Analysis (GSEA), Onto-Tools Pathway-Express uses a systems biology approach to identify pathways that are significantly impacted in any condition monitored by highthroughput gene expression technology. This new Impact Factor Analysis not only incorporates the classical probabilistic component but also includes important biological factors that are not captured by the existing techniques; e.g., the magnitude of the expression changes of each gene, the position of the differentially expressed genes on given pathways, the topology of the pathway that describes how genes interact, and the type of signaling interactions between them [64]. Based on a given set of input genes, for each pathway detected, a perturbation factor gamma $\mathrm{P}$ value and a corresponding FDR were calculated, taking into consideration the normalized FC of the gene and the number of genes upstream of its position in the pathway. Because IPA and Onto-Tools Pathway-Express have applied distinct statistical algorithms based on independent knowledge databases, these two bioinformatics tools are complementary, and thus their results are combined.

\section{Additional files}

Additional file 1: Figure S1. Diagram of sample selection and grouping of responders and non-responders to TPM treatment and Placebo for Weeks 8 and 12 .

Additional file 2: Tables S1-4. A detailed list of genes and pathways identified from the study at different treatment times.

\section{Competing interests}

E Yu serves as a member of the scientific advisory board for US WorldMeds, LLC. MD Li serves as a board member for ADial Pharmaceuticals. B A Johnson has served as a consultant to Johnson \& Johnson (Ortho-McNeil Janssen Scientific Affairs, LLC), Transcept Pharmaceuticals, Inc., D\&A Pharma, Organon, ADial Pharmaceuticals, Psychological Education Publishing Company (PEPCO LLC), and Eli Lilly and Company. All other authors report no competing interests.

\section{Authors contributions}

NA-D, JC, WH, DJM, DW, MMC, CS, RK, El, EY, AE, and BAJ participated in the clinical trial and contributed to both clinical and biological data collection $\mathrm{MDL}, J W, T N, J Z M, C S, D W, J S$, and RM undertook the management, and statistical and bioinformatics analysis of data. MDL, JW, TN, and CS were involved in the interpretation of results and in writing of the manuscript. All authors contributed to and have approved the final manuscript.

\section{Acknowledgments}

The clinical trial data used for this study are registered in Clinicaltrials.gov with the identifier: NCT00345371. We are grateful for the invaluable contributions of clinical information and blood samples by all participants in this clinical trial, as well as the dedicated work of many research staff at the clinical sites. We are grateful to the National Institute on Drug Abuse for its generous support through the Department of Veterans Affairs Cooperative Studies Program (Interagency Agreement No. Y1-DA4006). In addition, statistical and bioinformatics analyses of expression data were in part supported by NIH grant DA-137873 to MDL and an $\mathrm{NIH}$ contract to IMC.

\section{Author details}

'Department of Psychiatry and Neurobehavioral Sciences, University of Virginia, Charlottesville, USA. ${ }^{2}$ Information Management Consultants, Reston, USA. ${ }^{3}$ Department of Psychiatry, University of Missouri, Kansas City, USA. ${ }^{4}$ Pacific Addiction Research Center, Honolulu, USA. ${ }^{5}$ South Bay Treatment Center, San Diego, USA. ${ }^{6}$ Lutheran Hospital Office of Research, Des Moines, USA. ${ }^{7}$ Matrix Institute on Addictions, West Los Angeles, USA. ${ }^{8}$ Department of Veterans Affairs, Salt Lake City Health Care System, Salt Lake City, USA.

${ }^{9}$ Division of Pharmacotherapies and Medical Consequences of Drug Abuse, NIDA, Bethesda, USA. ${ }^{10}$ Veterans Administration Medical Center, Philadelphia, USA. " ${ }^{11}$ Department of Psychiatry, University of Maryland, Baltimore, USA.

${ }^{12}$ Department of Veterans Affairs Cooperative Studies Program Coordination Center, Perry Point, USA.

Received: 31 July 2013 Accepted: 19 November 2014

Published online: 12 December 2014

\section{References}

1. Yang MH, Jung MS, Lee MJ, Yoo KH, Yook YJ, Park EY, Choi SH, Suh YJ, Kim KW, Park JH: Gene expression profiling of the rewarding effect caused by methamphetamine in the mesolimbic dopamine system. Mol Cells 2008, 26(2):121 130

2. Elkashef A, Vocci F, Hanson G, White J, Wickes W, Tiihonen J: Pharmacotherapy of methamphetamine addiction: an update. Subst Abus 2008, 29(3):31 49.

3. SAMHSA: Results from the 2007 National Survey on Drug Use and Health: National Findings. Office of Applied Studies, NSDUH Series H-34, DHHS Publication No. SMA 08 4343. Rockville, MD: 2008.

4. Akiyama K, Kanzaki A, Tsuchida K, Ujike H: Methamphetamine-induced behavioral sensitization and its implications for relapse of schizophrenia. Schizophr Res 1994, 12(3):251 257.

5. Anglin MD, Burke C, Perrochet B, Stamper E, Dawud-Noursi S: History of the methamphetamine problem. J Psychoactive Drugs 2000, 32(2):137 141.

6. Bisagno V, Ferguson D, Luine VN: Short toxic methamphetamine schedule impairs object recognition task in male rats. Brain Res 2002, 940(1 2):95 101. 
7. Nordahl TE, Salo R, Leamon M: Neuropsychological effects of chronic methamphetamine use on neurotransmitters and cognition: a review. J Neuropsychiatry Clin Neurosci 2003, 15(3):317 325

8. Schroder N, O Dell SJ, Marshall JF: Neurotoxic methamphetamine regimen severely impairs recognition memory in rats. Synapse 2003, 49(2):89 96.

9. Okochi T, Kishi T, Ikeda M, Kitajima T, Kinoshita Y, Kawashima K, Okumura T, Tsunoka T, Inada T, Yamada M, Uchimura N, lyo M, Sora I, Ozaki N, Ujike H, Iwata N: Genetic association analysis of NRG1 with methamphetamineinduced psychosis in a Japanese population. Prog Neuropsychopharmacol Biol Psychiatry 2009, 33(5):903 905.

10. Davidson C, Gow AJ, Lee TH, Ellinwood EH: Methamphetamine neurotoxicity: necrotic and apoptotic mechanisms and relevance to human abuse and treatment. Brain Res Brain Res Rev 2001, 36(1):1 22.

11. Ricaurte GA, Guillery RW, Seiden LS, Schuster CR, Moore RY: Dopamine nerve terminal degeneration produced by high doses of methylamphetamine in the rat brain. Brain Res 1982, 235(1):93 103.

12. Rocher C, Gardier AM: Effects of repeated systemic administration of $\mathrm{d}$-Fenfluramine on serotonin and glutamate release in rat ventral hippocampus: comparison with methamphetamine using in vivo microdialysis. Naunyn Schmiedebergs Arch Pharmacol 2001, 363(4):422 428.

13. Spina $M B$, Cohen $\mathrm{G}$ : Dopamine turnover and glutathione oxidation: implications for Parkinson disease. Proc Natl Acad Sci U S A 1989, 86(4):1398 1400

14. Tata DA, Yamamoto BK: Interactions between methamphetamine and environmental stress: role of oxidative stress, glutamate and mitochondrial dysfunction. Addiction 2007, 102(Suppl 1):49 60

15. Yamamoto BK, Zhu W: The effects of methamphetamine on the production of free radicals and oxidative stress. J Pharmacol Exp Ther 1998, 287(1):107 114.

16. Zhang X, Lee TH, Xiong X, Chen Q, Davidson C, Wetsel WC, Ellinwood EH: Methamphetamine induces long-term changes in GABAA receptor alpha2 subunit and GAD67 expression. Biochem Biophys Res Commun 2006, 351(1):300 305.

17. Johnson BA, Ait-Daoud N, Elkashef AM, Smith EV, Kahn R, Vocci F, Li SH, Bloch DA: A preliminary randomized, double-blind, placebo-controlled study of the safety and efficacy of ondansetron in the treatment of methamphetamine dependence. Int J Neuropsychopharmacol 2008, 11(1):1 14.

18. Maryanoff BE, Nortey SO, Gardocki JF, Shank RP, Dodgson SP: Anticonvulsant O-alkyl sulfamates. 2,3:4,5-Bis-O-(1-methylethylidene)beta-D-fructopyranose sulfamate and related compounds. J Med Chem 1987, 30(5):880 887

19. Johnson BA, Ait-Daoud N, Bowden CL, DiClemente CC, Roache JD, Lawson K, Javors MA, Ma JZ: Oral topiramate for treatment of alcohol dependence: a randomised controlled trial. Lancet 2003, 361(9370):1677 1685

20. Johnson BA, Ait-Daoud N, Akhtar FZ, Javors MA: Use of oral topiramate to promote smoking abstinence among alcohol-dependent smokers: a randomized controlled trial. Arch Intern Med 2005, 165(14):1600 1605

21. Kampman KM, Pettinati H, Lynch KG, Dackis C, Sparkman T, Weigley C, OBrien CP: A pilot trial of topiramate for the treatment of cocaine dependence. Drug Alcohol Depend 2004, 75(3):233 240.

22. Johnson BA, Roache JD, Ait-Daoud N, Wells LT, Wallace CL, Dawes MA, Liu L, Wang XQ: Effects of topiramate on methamphetamine-induced changes in attentional and perceptual-motor skills of cognition in recently abstinent methamphetamine-dependent individuals. Prog Neuropsychopharmacol Biol Psychiatry 2007, 31(1):123 130

23. Johnson BA, Roache JD, Ait-Daoud N, Wells LT, Wallace CL, Dawes MA, Liu L, Wang XQ: Effects of acute topiramate dosing on methamphetamineinduced subjective mood. Int J Neuropsychopharmacol 2007, 10(1):85 98.

24. Johnson BA, Wells LT, Roache JD, Wallace CL, Ait-Daoud N, Dawes MA, Liu L, Wang $X Q$, Javors MA: Kinetic and cardiovascular effects of acute topiramate dosing among non-treatment-seeking, methamphetaminedependent individuals. Prog Neuropsychopharmacol Biol Psychiatry 2007, 31(2):455 461.

25. Zullino DF, Benguettat $D$, Khazaal $Y$ : Improvement of cognitive performance by topiramate: Blockage of automatic processes may be the underlying mechanism. Prog Neuropsychopharmacol Biol Psychiatry 2007, 31(3):787.

26. Elkashef A, Kahn R, Yu E, Iturriaga E, Li SH, Anderson A, Chiang N, Ait-Daoud N, Weiss D, McSherry F, Serpi T, Rawson R, Hrymoc M, Weis D, McCann M, Pham T, Stock C, Dickinson R, Campbell J, Gorodetzky C, Haning W, Carlton B, Mawhinney J, Li MD, Johnson BA: Topiramate for the treatment of methamphetamine addiction: a multi-center placebo-controlled trial. Addiction 2012, 107(7):1297 1306.

27. Mizoguchi H, Yamada K, Mizuno M, Mizuno T, Nitta A, Noda Y, Nabeshima T: Regulations of methamphetamine reward by extracellular signal-regulated kinase 1/2/ets-like gene-1 signaling pathway via the activation of dopamine receptors. Mol Pharmacol 2004, 65(5):1293 1301

28. Kauer JA, Malenka RC: Synaptic plasticity and addiction. Nat Rev Neurosci 2007, 8(11):844 858.

29. Narita M, Miyatake M, Shibasaki M, Tsuda M, Koizumi S, Yajima Y, Inoue K, Suzuki T: Long-lasting change in brain dynamics induced by methamphetamine: enhancement of protein kinase C-dependent astrocytic response and behavioral sensitization. J Neurochem 2005, 93(6):1383 1392.

30. Raffa RB, Finno KE, Tallarida CS, Rawls SM: Topiramate-antagonism of L-glutamate-induced paroxysms in planarians. Eur J Pharmacol 2010, 649(1 3):150 153.

31. Rawls SM, Thomas T, Adeola M, Patil T, Raymondi N, Poles A, Loo M, Raffa RB: Topiramate antagonizes NMDA- and AMPA-induced seizure-like activity in planarians. Pharmacol Biochem Behav 2009, 93(4):363 367.

32. Eun JW, Kwack SJ, Noh JH, Jung KH, Kim JK, Bae HJ, Xie H, Ryu JC, Ahn YM, Park WS, Lee JY, Rhee GS, Nam SW: Identification of post-generation effect of 3,4-methylenedioxymethamphetamine on the mouse brain by large-scale gene expression analysis. Toxicol Lett 2010, 195(1):60 67.

33. Simoes PF, Silva AP, Pereira FC, Marques E, Grade S, Milhazes N, Borges F, Ribeiro CF, Macedo TR: Methamphetamine induces alterations on hippocampal NMDA and AMPA receptor subunit levels and impairs spatial working memory. Neuroscience 2007, 150(2):433 441.

34. Betancur C, Sakurai T, Buxbaum JD: The emerging role of synaptic cell-adhesion pathways in the pathogenesis of autism spectrum disorders. Trends Neurosci 2009, 32(7):402 412.

35. Schluter OM, Xu W, Malenka RC: Alternative N-terminal domains of PSD-95 and SAP97 govern activity-dependent regulation of synaptic AMPA receptor function. Neuron 2006, 51(1):99 111.

36. Nakagawa T, Futai K, Lashuel HA, Lo I, Okamoto K, Walz T, Hayashi Y, Sheng M: Quaternary structure, protein dynamics, and synaptic function of SAP97 controlled by L27 domain interactions. Neuron 2004, 44(3):453 467.

37. Mehta S, Wu H, Garner CC, Marshall J: Molecular mechanisms regulating the differential association of kainate receptor subunits with SAP90/PSD-95 and SAP97. J Biol Chem 2001, 276(19):16092 16099.

38. Wang L, Piserchio A, Mierke DF: Structural characterization of the intermolecular interactions of synapse-associated protein-97 with the NR2B subunit of N-methyl-D-aspartate receptors. J Biol Chem 2005, 280(29):26992 26996.

39. Mauceri D, Gardoni F, Marcello E, Di Luca M: Dual role of CaMKII-dependent SAP97 phosphorylation in mediating trafficking and insertion of NMDA receptor subunit NR2A. J Neurochem 2007, 100(4):1032 1046

40. Suh YH, Terashima A, Petralia RS, Wenthold RJ, Isaac JT, Roche KW, Roche PA: A neuronal role for SNAP-23 in postsynaptic glutamate receptor trafficking. Nat Neurosci 2010, 13(3):338 343.

41. Wienecke J, Westerdahl AC, Hultborn H, Kiehn O, Ryge J: Global gene expression analysis of rodent motor neurons following spinal cord injury associates molecular mechanisms with development of postinjury spasticity. J Neurophysiol 2010, 103(2):761 778.

42. Hiraoka S, Kajii Y, Kuroda Y, Umino A, Nishikawa T: The development- and phencyclidine-regulated induction of synapse-associated protein-97 gene in the rat neocortex. Eur Neuropsychopharmacol 2010, 20(3):176 186.

43. Takaki M, Ujike H, Kodama M, Takehisa Y, Nakata K, Kuroda S: Two kinds of mitogen-activated protein kinase phosphatases, MKP-1 and MKP-3, are differentially activated by acute and chronic methamphetamine treatment in the rat brain. J Neurochem 2001, 79(3):679 688.

44. Bhat R, Axtell R, Mitra A, Miranda M, Lock C, Tsien RW, Steinman L: Inhibitory role for GABA in autoimmune inflammation. Proc Natl Acad Sci U S A 2010, 107(6):2580 2585.

45. Sequeira A, Turecki G: Genome wide gene expression studies in mood disorders. OMICS 2006, 10(4):444 454.

46. Churchill GA: Fundamentals of experimental design for CDNA microarrays. Nat Genet 2002, 32(Suppl 2):490 495.

47. van Leeuwen DM, van Agen E, Gottschalk RW, Vlietinck R, Gielen M, van Herwijnen MH, Maas LM, Kleinjans JC, van Delft JH: Cigarette smoke-induced differential gene expression in blood cells from monozygotic twin pairs. Carcinogenesis 2007, 28(3):691 697. 
48. Lampe JW, Stepaniants SB, Mao M, Radich JP, Dai H, Linsley PS, Friend SH, Potter JD: Signatures of environmental exposures using peripheral leukocyte gene expression: tobacco smoke. Cancer Epidemiol Biomarkers Prev 2004, 13(3):445 453.

49. Borovecki F, Lovrecic L, Zhou J, Jeong H, Then F, Rosas HD, Hersch SM, Hogarth P, Bouzou B, Jensen RV, Krainc D: Genome-wide expression profiling of human blood reveals biomarkers for Huntingtons disease. Proc Natl Acad Sci U S A 2005, 102(31):11023 11028.

50. Whitney AR, Diehn M, Popper SJ, Alizadeh AA, Boldrick JC, Relman DA, Brown PO: Individuality and variation in gene expression patterns in human blood. Proc Natl Acad Sci U S A 2003, 100(4):1896 1901.

51. Dumeaux V, Johansen J, Borresen-Dale AL, Lund E: Gene expression profiling of whole-blood samples from women exposed to hormone replacement therapy. Mol Cancer Ther 2006, 5(4):868 876.

52. Sullivan PF, Fan C, Perou CM: Evaluating the comparability of gene expression in blood and brain. Am J Med Genet B Neuropsychiatr Genet 2006, 141B(3):261 268.

53. Cai C, Langfelder P, Fuller TF, Oldham MC, Luo R, van den Berg LH, Ophoff RA, Horvath S: Is human blood a good surrogate for brain tissue in transcriptional studies? BMC Genomics 2010, 11:589.

54. Li C: Automating dChip: toward reproducible sharing of microarray data analysis. BMC Bioinformatics 2008, 9:231.

55. Irizarry RA, Bolstad BM, Collin F, Cope LM, Hobbs B, Speed TP: Summaries of Affymetrix GeneChip probe level data. Nucleic Acids Res 2003, 31(4):e15.

56. Gautier L, Cope L, Bolstad BM, Irizarry RA: Affy analysis of Affymetrix GeneChip data at the probe level. Bioinformatics 2004, 20(3):307 315

57. Calza S, Raffelsberger W, Ploner A, Sahel J, Leveillard T, Pawitan Y: Filtering genes to improve sensitivity in oligonucleotide microarray data analysis. Nucleic Acids Res 2007, 35(16):e102.

58. McClintick JN, Edenberg HJ: Effects of filtering by Present call on analysis of microarray experiments. BMC Bioinformatics 2006, 7:49.

59. Rowe WB, Blalock EM, Chen KC, Kadish I, Wang D, Barrett JE, Thibault O, Porter NM, Rose GM, Landfield PW: Hippocampal expression analyses reveal selective association of immediate-early, neuroenergetic, and myelinogenic pathways with cognitive impairment in aged rats. J Neurosci 2007, 27(12):3098 3110.

60. Mutch DM, Berger A, Mansourian R, Rytz A, Roberts MA: The limit fold change model: a practical approach for selecting differentially expressed genes from microarray data. BMC Bioinformatics 2002, 3:17.

61. Benjamini $Y$, Hochberg $Y$ : Controlling the false discovery rate: a practical and powerful approach to multiple testing. J Royal Stat Soc Series B 1995 57(1):289 300 .

62. Nakatani N, Hattori E, Ohnishi T, Dean B, Iwayama Y, Matsumoto I, Kato T, Osumi N, Higuchi T, Niwa S, Yoshikawa T: Genome-wide expression analysis detects eight genes with robust alterations specific to bipolar I disorder: relevance to neuronal network perturbation. Hum Mol Genet 2006, 15(12):1949 1962.

63. Dozmorov MG, Kyker KD, Hauser PJ, Saban R, Buethe DD, Dozmorov I, Centola MB, Culkin DJ, Hurst RE: From microarray to biology: an integrated experimental, statistical and in silico analysis of how the extracellular matrix modulates the phenotype of cancer cells. BMC Bioinformatics 2008, 9(Suppl 9):S4.

64. Draghici S, Khatri P, Tarca AL, Amin K, Done A, Voichita C, Georgescu C, Romero R: A systems biology approach for pathway level analysis. Genome Res 2007, 17(10):1537 1545.

65. Khatri P, Sellamuthu S, Malhotra P, Amin K, Done A, Draghici S: Recent additions and improvements to the Onto-Tools. Nucleic Acids Res 2005, 33(Web Server issue):W762 W765.

doi:10.1186/s12920-014-0065-x

Cite this article as: Li et al:: Transcriptome profiling and pathway analysis of genes expressed differentially in participants with or without a positive response to topiramate treatment for methamphetamine addiction. BMC Medical Genomics 2014 7:65.

\section{Submit your next manuscript to BioMed Central and take full advantage of:}

$\nabla$ Convenient online submission

$\otimes$ Thorough peer review

$\otimes$ No space constraints or color $\nabla$ gure charges

$\otimes I m m e d i a t e$ publication on acceptance

$\triangle$ Inclusion in PubMed, CAS, Scopus and Google Scholar

$\otimes$ Research which is freely available for redistribution

Submit your manuscript at www.biomedcentral.com/submit
() Biomed Central 